\title{
Numerical modelling and experimental study of heat and moisture properties of a wall based on date palm fibers concrete
}

\author{
Tarek Alioua ${ }^{1,2}$, Boudjemaa Agoudjil $^{1}$, and Abderrahim Boudenne, ${ }^{2, *}$ \\ ${ }^{1}$ Batna 1 University, LPEA Laboratory. 05000, Algeria \\ ${ }^{2}$ Université Paris Est Creteil/CERTES, 61 Av. du General de Gaulle, 94010 Creteil Cedex, France
}

\begin{abstract}
In the present paper, we study with both experimental and numerical aspect the heat and moisture transfer properties of a wall based on concrete filled with the natural fibers. The wall was placed in climatic chamber and temperature and relative humidity were monitored at different depths. A developed model describing heat and moisture transfers in porous building materials was implemented in COMSOL Multiphysics and solved with the finite element method. The obtained results are compared with experimental data. A relatively good agreement was obtained for both temperature and relative humidity variation at different depths. Finally, the developed model gives almost a good prediction despite the classical difficulties encountered at the experiment, which is very promising for the prediction of the hygrothermal behavior of bio-based building materials at different conditions.
\end{abstract}

\section{Introduction}

The recent resorting to using environmentally friendly building materials was accompanied by a fast development of mathematical models describing heat and mass transfers in this type of materials. Adding natural fibers to building materials makes them highly porous, storing considerable amounts of heat and moisture. This feature thus added complexity to these mathematical models due to the strongly coupled thermal and hygric resulted phenomena.

Recently, a considerable number of experimental studies were carried out at material and wall scales to study physical, thermal and hydric properties of biobased building materials [1,2]. After that, the need for predictions under various climatic conditions at different scales pushed researchers to develop mathematical models which predict temperature and humidity profiles in building materials. The origin of most models is a model build by Phillip and De Vries [3], different works use this model and refer to Mendes et al. [4] who has deeply investigated this model performing a sensitivity analysis [5]. Lately, another work dedicated for building materials was carried out by Kunzel et al. [6], which doesn't take into account thermal gradients. In the present work, a model was developed based on Kunzel's work, then solved numerically and results were compared with experimental data obtained from a conducted test on a wall made of date palm fibers concrete.

\section{Materials and methods}

\subsection{Material properties}

The tested wall is made of Date Palm Fibers Concrete (DPFC) with $50 \mathrm{~cm} \times 40 \mathrm{~cm} \times 15 \mathrm{~cm}$ of dimension (Fig. 1). This bio-composite is consisting with ordinary mortar reinforced with 15 wt. \% of date palm fibers. According to our previous works, this formulation has shown interesting thermo-physical, mechanical and hygric properties (Table 1) [2].

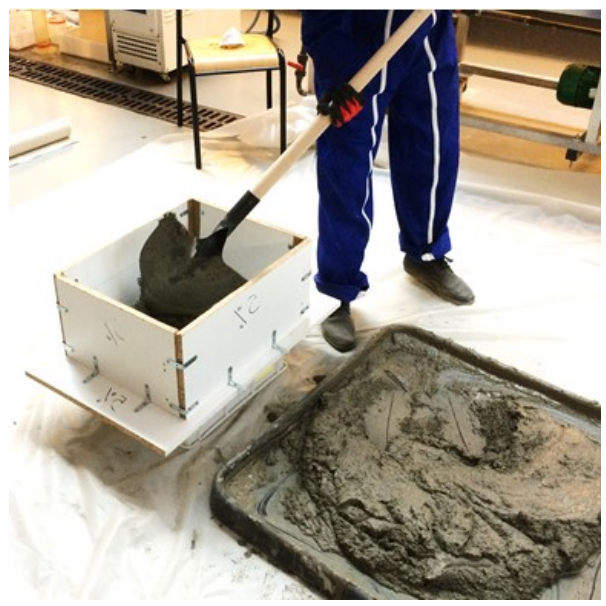

Fig. 1. Preparation of DPFC wall.

\footnotetext{
* Corresponding author: boudenne@u-pec.fr
} 


\begin{tabular}{|c|c|}
\hline \\
\hline $\begin{array}{l}\text { Nomenclature } \\
b \quad \text { moisture sunplement coefficient }(\% / \%)\end{array}$ & moisture supplement coefficient (\%/\%) \\
\hline$c_{0}$ & material specific heat at dry state $(\mathrm{J} / \mathrm{kgK})$ \\
\hline$c_{l}$ & liquid specific heat $(\mathrm{J} / \mathrm{kgK})$ \\
\hline$c_{v}$ & vapor specific heat $(\mathrm{J} / \mathrm{kgK})$ \\
\hline$D_{l}$ & $\begin{array}{l}\text { liquid transport coefficient under relative } \\
\text { humidity gradient }(\mathrm{kg} / \mathrm{ms})\end{array}$ \\
\hline$D_{T}$ & $\begin{array}{l}\text { mass transport coefficient under thermal } \\
\text { gradient }\left(\mathrm{m}^{2} / \mathrm{Ks}\right)\end{array}$ \\
\hline$D_{T, v}$ & $\begin{array}{l}\text { vapor transport coefficient under thermal } \\
\text { gradient }\left(\mathrm{m}^{2} / \mathrm{Ks}\right)\end{array}$ \\
\hline$D_{T, l}$ & $\begin{array}{l}\text { liquid transport coefficient under thermal } \\
\text { gradient }\left(\mathrm{m}^{2} / \mathrm{Ks}\right)\end{array}$ \\
\hline$D_{w}$ & $\begin{array}{l}\text { mass transport coefficient under water } \\
\text { content gradient }\left(\mathrm{m}^{2} / \mathrm{s}\right)\end{array}$ \\
\hline$D_{w, v}$ & $\begin{array}{l}\text { vapor transport coefficient under water } \\
\text { content gradient }\left(\mathrm{m}^{2} / \mathrm{s}\right)\end{array}$ \\
\hline$D_{w, l}$ & $\begin{array}{l}\text { liquid transport coefficient under water } \\
\text { content gradient }\left(\mathrm{m}^{2} / \mathrm{s}\right)\end{array}$ \\
\hline G & vapor flux at the boundary surface $\left(\mathrm{kg} / \mathrm{m}^{2} \mathrm{~s}\right)$ \\
\hline$h$ & $\begin{array}{l}\text { convective heat transport coefficient } \\
\left(\mathrm{W} / \mathrm{m}^{2} \mathrm{~K}\right)\end{array}$ \\
\hline$l_{v}$ & latent heat of vaporization $(\mathrm{J} / \mathrm{kg})$ \\
\hline$Q$ & heat flux at the boundary surface $\left(\mathrm{W} / \mathrm{m}^{2}\right)$ \\
\hline$t$ & time $(\mathrm{s})$ \\
\hline$T$ & temperature $(\mathrm{K})$ \\
\hline $\begin{array}{l}p_{\text {sat }} \\
w\end{array}$ & $\begin{array}{l}\text { vapor saturation pressure }(\mathrm{Pa}) \\
\text { water content }\left(\mathrm{kg} / \mathrm{m}^{3}\right)\end{array}$ \\
\hline$\beta$ & water vapor transfer coefficient $\left(\mathrm{kg} / \mathrm{m}^{2} \mathrm{sPa}\right)$ \\
\hline$\delta$ & $\begin{array}{l}\text { water vapor permeability of the material } \\
(\mathrm{kg} / \mathrm{msPa})\end{array}$ \\
\hline $\begin{array}{l}\delta_{a} \\
\xi_{\psi}\end{array}$ & $\begin{array}{l}\text { water vapor permeability of air }(\mathrm{kg} / \mathrm{msPa}) \\
\text { hygric capacity }\left(\mathrm{kg} / \mathrm{m}^{3} \%\right)\end{array}$ \\
\hline$\lambda$ & thermal conductivity $(\mathrm{W} / \mathrm{mK})$ \\
\hline$\rho_{0}$ & material density at dry state $\left(\mathrm{kg} / \mathrm{m}^{3}\right)$ \\
\hline$\rho_{l}$ & liquid water density $\left(\mathrm{kg} / \mathrm{m}^{3}\right)$ \\
\hline$\psi$ & relative humidity $(\%)$ \\
\hline Scripts: & \\
\hline 0 & at dry state \\
\hline$a m b$ & ambient \\
\hline$r e f$ & reference \\
\hline surf & at wall surface \\
\hline
\end{tabular}

Table 1. DPFC properties.

\begin{tabular}{lccc}
\hline Property & value & Property & value \\
\hline $\begin{array}{l}\text { Dry density } \\
{\left[\mathrm{kg} / \mathrm{m}^{3}\right]}\end{array}$ & 954 & $\begin{array}{c}\text { Vapor resistance } \\
\text { factor (dry cup) [- }]\end{array}$ & 6.31 \\
\hline $\begin{array}{l}\text { Porosity } \\
{\left[\mathrm{m}^{3} / \mathrm{m}^{3}\right]}\end{array}$ & 0.64 & $\begin{array}{c}\text { Vapor resistance } \\
\text { factor (wet cup) }[-]\end{array}$ & 5.57 \\
\hline $\begin{array}{l}\text { Dry specific heat } \\
{[\mathrm{J} / \mathrm{kgK}]}\end{array}$ & 1500 & $\begin{array}{c}\text { Thermal conductivity } \\
\text { at } 23^{\circ} \mathrm{C}[\mathrm{W} / \mathrm{mK}]\end{array}$ & 0.23 \\
\hline
\end{tabular}

Sorption isotherm characterizes any material that can hold moisture. This curve describes the evolution of water content inside the material as a function of relative humidity variation. For DPFC it was obtained experimentally by [2] (Fig. 2).

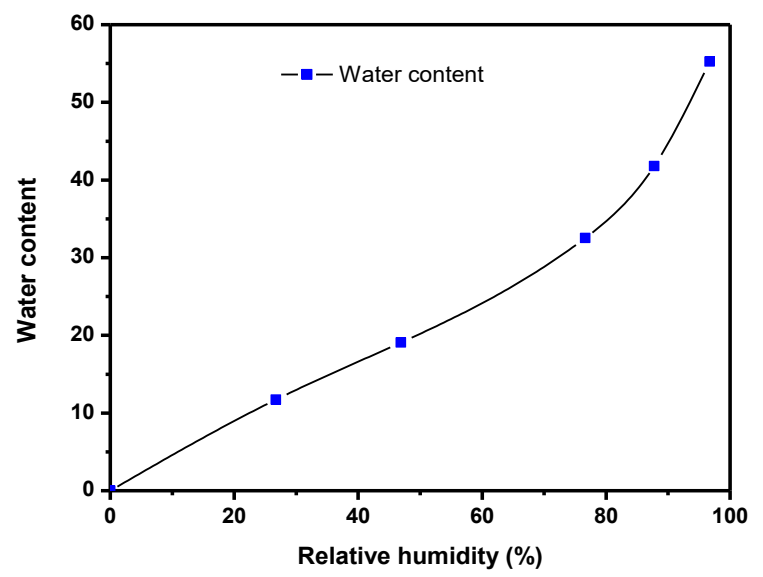

Fig. 2. Sorption curve of DPFC.

\subsection{Mathematical model}

In this work, the used mathematical model was developed by Kunzel [6] and reformulated by Aït Ouméziane [7]. The transfer modes considered for moisture transfer are liquid and vapor diffusion, while modes of heat transfer are conduction and enthalpy flows (phase change and sensitive heat). Note that air transfer is not considered in this study for the weak air pressure gradients between the right and left external surfaces of the wall [8]. The resulted 1D conservation equations are the following [7]:

Moisture transfer:

$$
\xi_{\psi} \frac{d \psi}{d t}=\nabla\left[\delta \nabla\left(p_{s a t} \psi\right)+D_{l} \nabla \psi\right]
$$

Heat trans

$$
\begin{gathered}
\left(\rho_{0} c_{0}+c_{l} w\right) \frac{d T}{d t}= \\
\nabla\left\{\lambda \nabla T+\left[l_{v}+c_{v}\left(T-T_{r e f}\right)\right]\left[\delta \nabla\left(p_{s a t} \psi\right)\right]\right\}+ \\
\nabla\left[c_{l}\left(T-T_{r e f}\right) D_{l} \nabla \psi\right]
\end{gathered}
$$

As boundary conditions, we only consider heat and mass fluxes at boundaries [6]:

$$
\begin{aligned}
& Q=h\left(T_{\text {surf }}-T_{\text {amb }}\right) \\
& G=\beta\left(P_{v, \text { surf }}-P_{v, a m b}\right)
\end{aligned}
$$

where

$$
\beta=7.10^{-9} . h
$$

\subsection{Model validation}

Several validation tests have been performed by [7] against HAMSTAD WP2 [9] international benchmark, using a set of numerical data available for public. The used mathematical model in this benchmark was based on [10]. Several researchers provided numerical solutions of this model, using different software packages and numerical techniques. Some works were 
based on finite difference, while other ones on finite volume or finite element. Moreover, both explicit or implicit time discretization schemes have been used. The discretization strategies (constant or adaptive time steps and mesh) were also different, as well as the way treating non-linear phenomena (i.e. interpretation of interface conductivity) and the applied convergence criteria (absolute, relative) etc. [11].

The described model in our work has been implemented in COMSOL Multiphysics and Matlab software for five different configuration tests (Insulated roof, Homogeneous wall, Light weight wall, Response analysis and Capillary active inside insulation) and for different materials. The results showed a good agreement between the used model and the other numerical solutions for all the studied cases. In conclusion, we can apply this model for our study using a single layer homogenous wall under temperature and relative humidity variations.

\section{Experimental protocol and simulation}

\subsection{Experimental protocol}

The wall of $50 \mathrm{~cm} \times 40 \mathrm{~cm} \times 15 \mathrm{~cm}$ (Fig. 3.a) was placed inside the climatic chamber (Fig. 3.b); and subjected to various climatic conditions (step functions of temperature and relative humidity are presented in Table 2 ). The goal of the insulation is to impose a $1 \mathrm{D}$ transfer and create temperature and relative humidity variation between the outdoor and indoor surfaces of the wall. In this work, we chose that the indoor conditions be not controlled. Whereas that the outdoor conditions are incrementally changed in order to create temperature or relative humidity gradients. Each step is followed by a conditioning phase at $\psi=50 \%$ and $\mathrm{T}=23^{\circ} \mathrm{C}$ until reached the equilibrium. Table 2 summarizes the room conditions and the measurement strategy used.

Table 2. Thermal properties of DPFC wall.

\begin{tabular}{cccc} 
& $\begin{array}{c}\text { Operating } \\
\text { parameter }\end{array}$ & $\mathrm{T}\left[{ }^{\circ} \mathrm{C}\right]$ & $\psi[\%]$ \\
\hline $\begin{array}{c}\text { Outdoor } \\
\text { conditions } \\
\text { subsection }\end{array}$ & $\begin{array}{c}\text { Scenario } 1 \\
\text { Scenario } 2 \\
\text { (stateady } \\
\text { state test) }\end{array}$ & $40 \rightarrow 18$ & 50 \\
\hline Scenario 3 & 23 & 50 \\
\hline
\end{tabular}

Fig. 3. Experimental setup and conditions.

\subsection{Simulation}

The model was implemented in COMSOL Multiphysics, a simulation software and partial differential equations solver based on the finite element numerical method. The implementation has been done through the PDE modes under the time dependent coefficient form PDE's, details on implementation can be found in $[12,13]$. The mesh was generated for default parameters according to [10]. The mesh sensitivity analysis has been carried out and discussed in section 3.1.

The same wall and boundary conditions were simulated (Fig. 4). The climatic conditions were exported from the experiment and applied directly to the simulated wall.

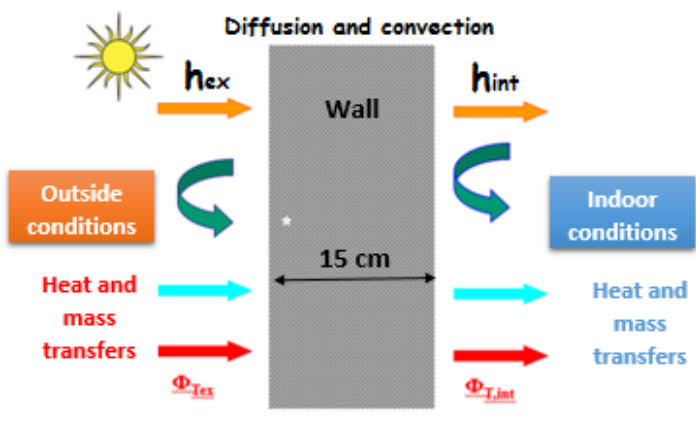

Fig. 4. Schematic view of the wall and boundary conditions

\section{Results and discussion}

The monitoring of relative humidity and temperature within the wall was performed using DKRF400 sensors. The numerical results of temperature and relative humidity variations for each scenario are compared to the experimental recorded values.

\subsection{Mesh impact}

The impact of mesh on numerical results has been tested. Generally, the studied wall of thickness $\mathrm{e} \mathrm{cm}$ is discretized into $n$ nodes, and thus into (n-1) layers. The elementary thickness " $\mathrm{dx}$ » of each layer is then equal to: $\mathrm{dx}=\mathrm{e} /(\mathrm{n}-1)$. Several criterions take place when we want to choose mesh, such as calculation accuracy, results convergence and calculation time. In this work, three different refining levels have been examined: 10 elements, 50 elements and 760 elements.

Table 3. Calculation time depending on mesh elements.

\begin{tabular}{lccc}
\hline Number mesh elements & 10 & 50 & 760 \\
\hline $\begin{array}{l}\text { Calculation time for heat } \\
\text { transfer }\end{array}$ & $\begin{array}{c}1137 \\
\mathrm{sec}\end{array}$ & $\begin{array}{c}1.525 \\
\mathrm{sec}\end{array}$ & $\begin{array}{c}29 \\
\mathrm{sec}\end{array}$ \\
\hline $\begin{array}{l}\text { Calculation time for } \\
\text { moisture transfer }\end{array}$ & $\begin{array}{l}12 \mathrm{~min} \\
42 \mathrm{sec}\end{array}$ & $\begin{array}{c}35 \mathrm{~min} \\
26 \mathrm{sec}\end{array}$ & $\begin{array}{c}1 \mathrm{~h} 3 \mathrm{~min} \\
23 \mathrm{sec}\end{array}$ \\
\hline
\end{tabular}


As it can be clearly seen in Table 3 heat transfer problems resolution converge very faster than moisture transfer ones, for the raison that relative humidity variations imply the intervention of adsorption curve at every time step in order to calculate the water content.

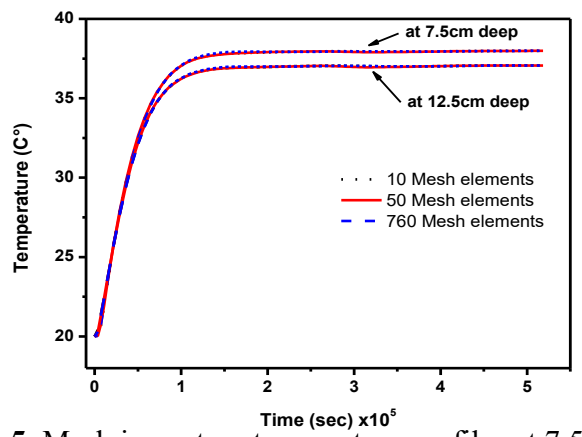

Fig. 5. Mesh impact on temperature profiles at $7.5 \mathrm{~cm}$ and 12.5 cm deep.

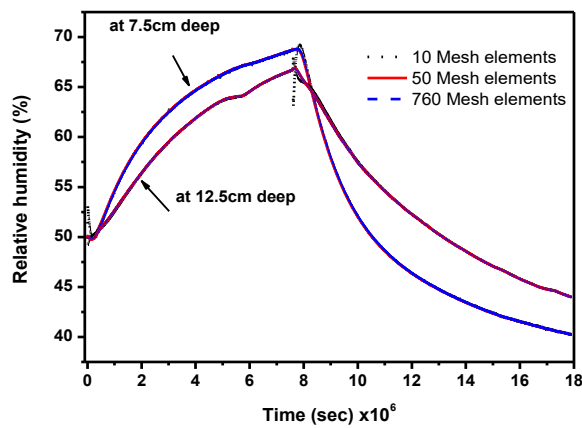

Fig. 6. Mesh impact on relative humidity profiles at $7.5 \mathrm{~cm}$ and $12.5 \mathrm{~cm}$ deep.

The results shown the mesh impact on the calculation of both temperature and relative humidity for two different depths $(7.5 \mathrm{~cm}$ and $12.5 \mathrm{~cm})$ are presented in Figs. 5, 6. We notice that for each depth, the difference of the estimated temperature is negligible to the mesh variation. For relative humidity case, the obtained results using only 10 mesh elements exhibit an important variation to the two other ones (50 and 760 mesh elements). However, the obtained results using these two last (50 and 760) are quite similar. These results show that in our case, all examined mesh levels are only acceptable for heat transfer resolution. However, for moisture transfer mesh needs to be more refined (around 50 elements or more). Relating to these results, we have chosen to use a triangular mesh of 3040 elements to ensure that we are far enough of any possible deviations since the calculation time is still relatively acceptable.

\subsection{Heat transfer}

Figs. 5, 6, 7 represent simulated and experimental temperature variations at $7.5 \mathrm{~cm}$ deep (the center) of the wall as a function of time variation. Fig. 5 shows the evolution of one cycle which correspond to the scenario 1 presented in table 2 (i.e. an increase of temperature of the outdoor side of the wall from $23^{\circ} \mathrm{C}$ to $40^{\circ} \mathrm{C}$ during $5 \times 10^{4}$ second followed by a decrease until $18^{\circ} \mathrm{C}$ at $\psi=$ $50 \%$ ). Fig. 6 shows the evolution of five cycles corresponding also to scenario 1 during $4.5 \times 10^{5}$ second. We notice that both experimental and numerical curves rise right after the excitation in the same way, with a maximum difference of $1^{\circ} \mathrm{C}$. During temperature drop, the experimental curve decreases faster than the simulated curve reaching a maximum difference of $3^{\circ} \mathrm{C}$. We also notice that the influence of initial conditions disappears after the first cycle (both curves reach the same top values whatever were the starting temperatures).

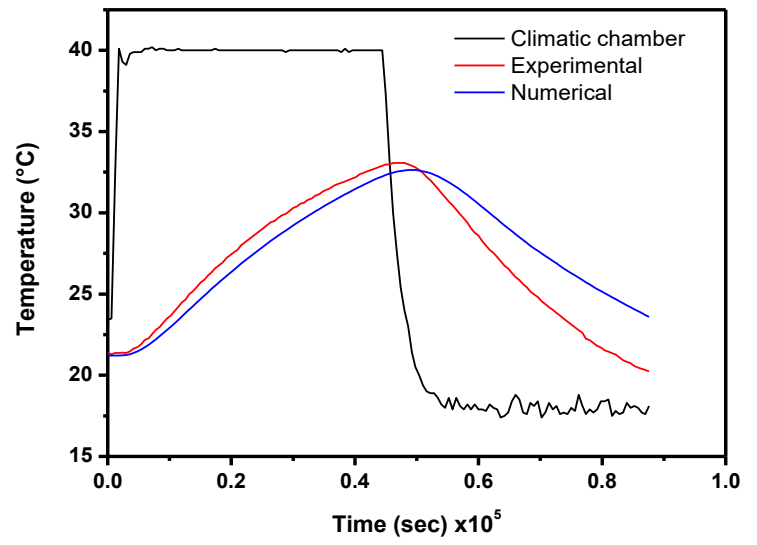

Fig. 7. Temperature variation at $7.5 \mathrm{~cm}$ deep (first cycle).

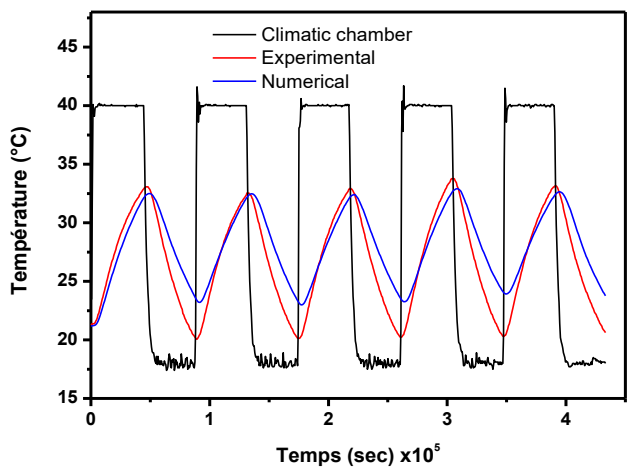

Fig. 8. Temperature variation at $7.5 \mathrm{~cm}$ deep (several cycles).

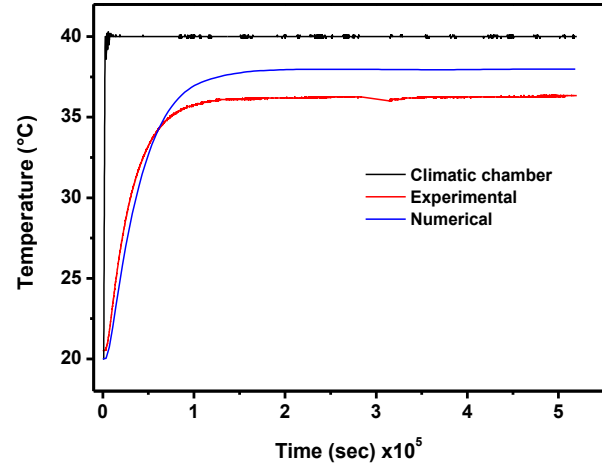

Fig. 9. Temperature steady state test at $7.5 \mathrm{~cm}$ deep.

Fig. 7 shows the steady state test where temperature is set to jump from $20^{\circ} \mathrm{C}$ to $40^{\circ} \mathrm{C}$ and kept constant at this value until values were stable (scenario 2, Table 2). We notice that the numerical and experimental curves react and reach the steady state almost at the same time $\left(38^{\circ} \mathrm{C}\right.$ and $36.25^{\circ} \mathrm{C}$ respectively). The numerical curve reached a temperature value greater than the 
experimental one, where phenomena is was also obtained by [14]. These results highlight the good agreement between the mathematical model and the experiment $[14,15]$.

\subsection{Moisture transfer}

Figs. 8, 9 represent simulated and experimental relative humidity evolution at $7.5 \mathrm{~cm}$ and $12.5 \mathrm{~cm}$ deep respectively from the outdoor surface of the wall as a function of time. In this case, we chose the scenario 3 with the application of $75 \%$ of the relative humidity during $6 \times 10^{5}$ seconds followed with a decrease until $33 \%$ during $10 \times 10^{5}$ seconds.

We notice that the measurements data of the relative humidity shows some fluctuation related to the difficulty of stabilization of the humidity in the climatic chamber.

As for temperature case, both simulated and experimental curves react immediately to the excitation, while for the second part of the step function, the simulated curve decreases quicker than the experimental one. This result is due to the hysteresis phenomenon in the experiment at desorption phase, while in simulation only adsorption curve was considered for both phases $[15,16]$. Maximum differences registered are $14 \%$ and $7 \%$ at $7.5 \mathrm{~cm}$ and $12.5 \mathrm{~cm}$ deep respectively. In general, good agreement especially at the rise and at deeper points was found, this result was found by [17] but for smaller amplitudes of relative humidity and different sensors accuracy. Note that at the beginning of the experiment, a sudden decrease in relative humidity was recorded, which surely has a direct influence on experimental profiles.

The varying differences for both temperature and relative humidity profiles between the simulation and the experiment may be attributed to several factors such as: the dependence of thermal conductivity on temperature and moisture content that should be considered in the model [2]; and the quality of insulation and sealing materials at the experiment.

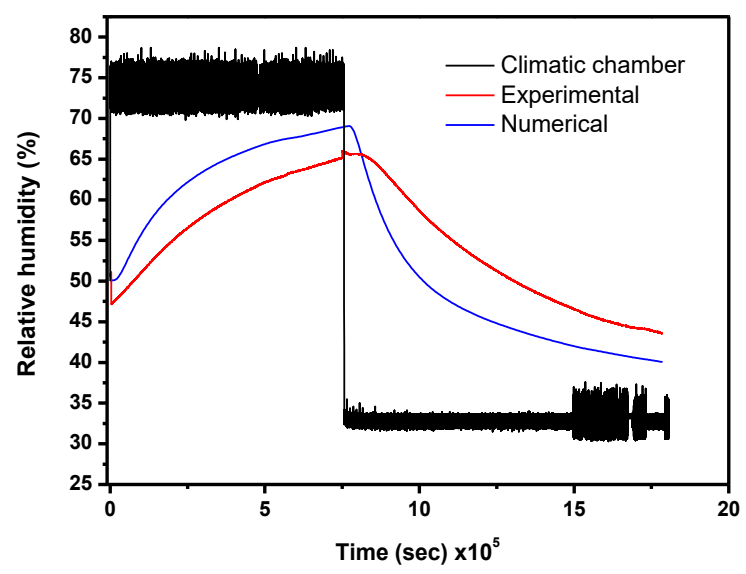

Fig. 10. Relative humidity variation at $7.5 \mathrm{~cm}$ deep.

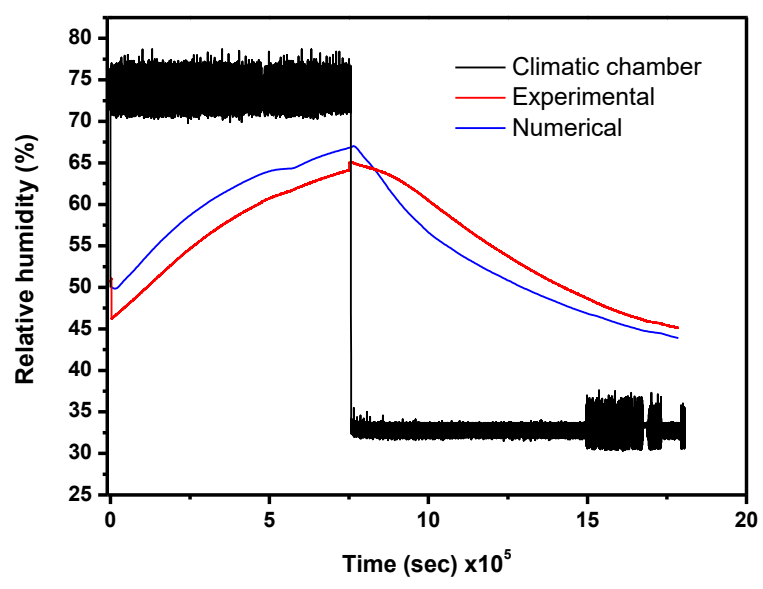

Fig. 11. Relative humidity variation at $12.5 \mathrm{~cm}$ deep.

\section{Conclusion}

In this work, we performed a validation of a mathematical model for heat and moisture transfer of bio-based building wall. We compared the thermal and hygric behaviors of the model with experimental data obtained from a wall based on date palm fibers concrete. Heat and mass conservation equations were presented as well as boundary conditions and material properties. To solve the equation system, they were implemented in COMSOL Multiphysics, that is adopted for partial differential equation systems. The same experimental conditions were regenerated in the software.

A global good agreement was found between the experimental and numerical results through temperature and relative humidity behavior. Better concordance was obtained during temperature rise, and at the deeper points of the wall for moisture transport. Note that the hysteresis effect on sorption curve has an important influence on results and thus should be taken into account for the next work. Finally, the present work highlights on the one hand, the validation of used mathematical model with experimental data. On other hand, and in our knowledge, this is the first study that use an hygrothermal model for the prediction of both temperature and relative humidity behavior of bio-based building wall (based on date palm fibers concrete) for different conditions.

This research was conducted with financial support of PHC TASSILI Project 16MDU976.

\section{References}

1. M. Rahim, O. Douzane, A.T. Le, G. Promis, B. Laidoudi, A. Crigny, B. Dupre, T. Langlet, Energy and Buildings, 88, 7 (2015)

2. B. Haba, B. Agoudjil, A. Boudenne, K Benzarti, Construction and Building Materials, 154, 9 (2017)

3. J.R. Philip, Journal of meteorology, 14(4), 13 (1957) 
4. N. Mendes, I. Ridley, R. Lamberts, P.C. Philippi, K. Budag, In Building Simulation ConferenceIBPSA, 99, 7 (1999)

5. N. Mendes, F.C. Winkelmann, R. Lamberts, P.C. Philippi, Energy and Buildings, 35(7), 14 (2003)

6. H.M Künzel, Simultaneous heat and moisture transport in building components. One-and twodimensional calculation using simple parameters. IRB-Verlag Stuttgart, 65 (1995)

7. Y. Aït Ouméziane, Evaluation des performances hygrothermiques d'une paroi par simulation numérique: application aux parois en béton de chanvre (Doctoral dissertation, Rennes, INSA), 351 (2013)

8. D. Lelièvre, Simulation numérique des transferts de chaleur et d'humidité dans une paroi multicouche de bâtiment en matériaux biosourcés (Doctoral dissertation, Lorient), 183 (2015)

9. C. E. Hagentoft, Report R-02: 8. Gothenburg, Department of Building Physics, Chalmers University of Technology, 5 (2002)

10. A. V. Luikov, Heat and mass transfer in capillaryporous bodies. In Advances in heat transfer. Elsevier. 1, 62 (1964)

11. C. E. Hagentoft, A. S. Kalagasidis, B. Adl-Zarrabi, S. Roels, J. Carmeliet, H. Hens, \& O. Adan, Journal of thermal envelope and building science, 27(4), 26 (2004)

12. A.J.P.M. Goesten, Heat, Air and Moisture transport in Building Constructions, Department of building environment, Eindhoven university of technology, 37 (2015)

13. Multiphysics, C. O. M. S. O. L. Version 3.5 a. User's guide, 624 (2005)

14. T. Colinart, P. Glouannec, T. Pierre, P. Chauvelon, \& A. Magueresse, Buildings, 3(1), 11 (2013)

15. Y. A. Oumeziane, M. Bart, S. Moissette, \& C. Lanos, Transport in porous media, 103(3) 19 (2014)

16. Y. Aït Oumeziane, S. Moissette, M. Bart, F. Collet, S. Pretot, C. Lanos, Journal of Building Performance Simulation, 10(3), 16 (2017)

17. C. Maalouf, A. T. Le, S. B. Umurigirwa, M. Lachi, \& O. Douzane, Energy and buildings, 77, 10 (2014) 